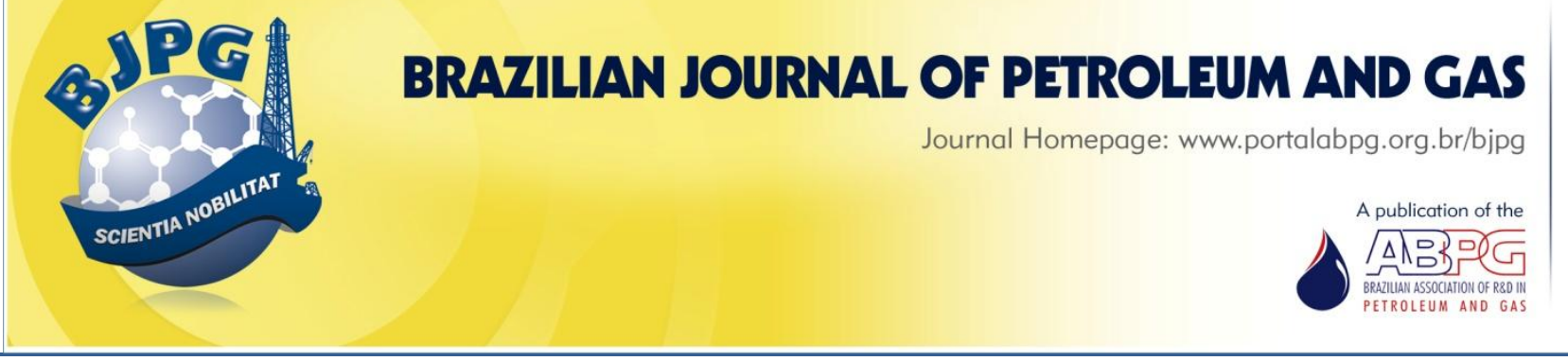

\title{
HYDROCYCLONE APPLICATIONS IN PRODUCED WATER: A STEADY-STATE NUMERICAL ANALYSIS
}

\author{
${ }^{a}$ Souza, J. S.; ${ }^{a}$ Paiva, M. K. N.; ${ }^{\text {}}$ Farias, F. P. M.; ${ }^{\text {}}$ Farias Neto, S. R.; ${ }^{\text {c }}$ Lima, A. G. B. ${ }^{1}$ \\ ${ }^{a}$ Federal University of Campina Grande, Department of Chemical Engineering, Campina Grande, Brazil \\ ${ }^{b}$ Federal University of Campina Grande, Department of Technology and Development, Campina Grande, Brazil \\ ${ }^{\mathrm{C}}$ Federal University of Campina Grande, Department of Mechanical Engineering, Campina Grande, Brazil
}

\begin{abstract}
Hydrocyclones are devices used to treat produced water in the petroleum industry. These gadgets are employed especially at offshore fields, due to restrictions of charge and space. Several factors may affect the performance of the oil/water separation by hydrocyclones. Among these factors are the geometry and processing capacity of the hydrocyclones, oil droplet size, density difference between the phases, pressure drops, and temperature fluctuation. This paper aims to analyze the effects of inlet fluid mixture temperature and oil droplet size on hydrocyclone performance in separating dispersed heavy oil from continuous streams of water. The experiment used a commercial package, ANSYS CFX 11. Numerical results clearly indicate that superficial velocity and oil mass flow rate in the overflow have a positive relationship with oil droplet size and temperature. The pressure drop decreased from 155.857 to $141.966 \mathrm{kPa}$ and the separation efficiency changed from 58.97 to $60.11 \%$ when the inlet temperature increased from 20 to $100^{\circ} \mathrm{C}$ using a $40 \mu \mathrm{m}$ oil droplet diameter.
\end{abstract}

\section{KEYWORDS}

produced water; two-phase oil flow; hydrocyclone; CFD

\footnotetext{
${ }^{1}$ To whom all correspondence should be addressed.

Address: Department of Mechanical Engineering, Federal University of Campina Grande, Av. Aprígio Veloso 82, Bodocongó,

Campina Grande -PB, Brazil - ZIP Code 58429-900

Telephone / Fax: +55 83 2101-1317 | E-mail: gilson@dem.ufcg.edu.br

doi:10.5419/bjpg2012-0011
} 


\section{INTRODUCTION}

The disposal of produced water during petroleum exploitation is known to causes serious environmental damage. In order to reduce the negative impact caused by produced water, it is necessary to perform a water treatment before disposing it into the environment. Such treatment has to follow the specific criteria established by environmental agencies in each Country. Environmental agencies do not allow the release of effluents from petroleum productions, which contain oil concentrations that exceed the amounts permitted by regulations. Based on the United States Environment Protection Agency (USEPA) regulations, the daily maximum limit for releasing oil and grease is $42 \mathrm{mg} / \mathrm{L}$, and the monthly average limit is $29 \mathrm{mg} / \mathrm{L}$. The Convention for the Protection of the Marine Environment of the North-East Atlantic, OSPAR Convention, stipulates the annual average limit for discharge of dispersed oil in produced water into the sea, $40 \mathrm{mg} / \mathrm{L}$. On offshore platforms, produced water can be discharged directly into the ocean provided the dispersed phase concentration of oil and grease is below a specified value. Such values range from $29 \mathrm{ppm}$ in the Gulf of Mexico and 20ppm in Brazil. In Norway, the oil operators have agreed to implement a policy of zero harmful discharges in the environment (Neff, 2002; Ahmadun et al., 2009; Souza et al., 2011; Vieira et al., 2012).

Several researches found in literature use cyclones or hydrocyclones in two-phase separation processes, considering the effects of temperature, fluid viscosity, oil droplet size, flow rate, and others parameters (Cillers and Harrison, 1997; Yoshida et al., 2004; Bennett and Williams, 2004; Xiang and Lee, 2005; Husveg et al., 2007).

Bennett and Williams (2004) reported that oil droplet size has a considerable influence on the rate of oil/water immiscible mixture separation. Commonly, a hydrocyclone feed containing oil in concentration ranging between 200 to 2000ppm can be reduced by a factor of 100 down to $20 \mathrm{ppm}$ and oil/water separation efficiency of $100 \%$ is generally achieved for droplet sizes greater than $50 \mu \mathrm{m}$. However, efficiencies drop significantly for droplet sizes smaller than $5 \mu \mathrm{m}$. These results are affected by different fluid physical parameters and geometrical characteristics of the hydrocyclone.
In industrial operations, the role of temperature may be critical, either due to climatic variations or because of active manipulation. In particular, the effects of temperature on oil/water recovery can be verified when hot liquids or steam circulates around the hydrocyclone's body to reduce oil viscosity, improving separation performance (Hashmi et al., 2004; Souza et al., 2011). Souza et al. (2011) studied the effects of oil droplet diameter in oil average temperature when hydrocyclone was used to separate oil from the water stream. The researchers observed an increase in temperature when increasing the oil droplet's diameter, which retained higher heat energy, favoring an increase in the temperature from 389 to $405 \mathrm{~K}$. Hashmi et al. (2004) studied the separation efficiency of a waste stream of oil/water using the CANMET hydrocyclone and evaluating the quality of the oil recovered in different concentrations of oil feed. These authors concluded that, for low oil concentrations, it was possible to recover the oil in the overflow of the hydrocyclone. However, for higher oil concentrations, the separation efficiency results were not promising.

The fluid pressure energy in the hydrocyclone is used to create a centrifugal field and to drag force generation, necessary to move the water/oil mixture into the hydrocyclone and improve oil recovery on the overflow. The hydrocyclone's efficiency was studied by Farias et al. (2011). These authors verified that the separation efficiency is affected by the inlet's solid concentration, reaching values between 90.3 and $99.12 \%$ in the underflow, while the oil concentration ranged from 77.8 to $98.82 \%$ in the overflow, representing a drop of $8.86 \%$ to solid particle separation efficiency and an increase of $11.91 \%$ for oil droplet separation efficiency.

Available literature lacks publications involving numerical works related to the influence of temperature on heavy-oil/water separation. Thus, this paper aims to present a numerical study of the flow behavior into the hydrocyclone during the oil/water separation process. It takes into account the influence of the temperature of the inlet fluid mixture and the diameter of oil droplet on the treatment of produced water by hydrocyclone. 


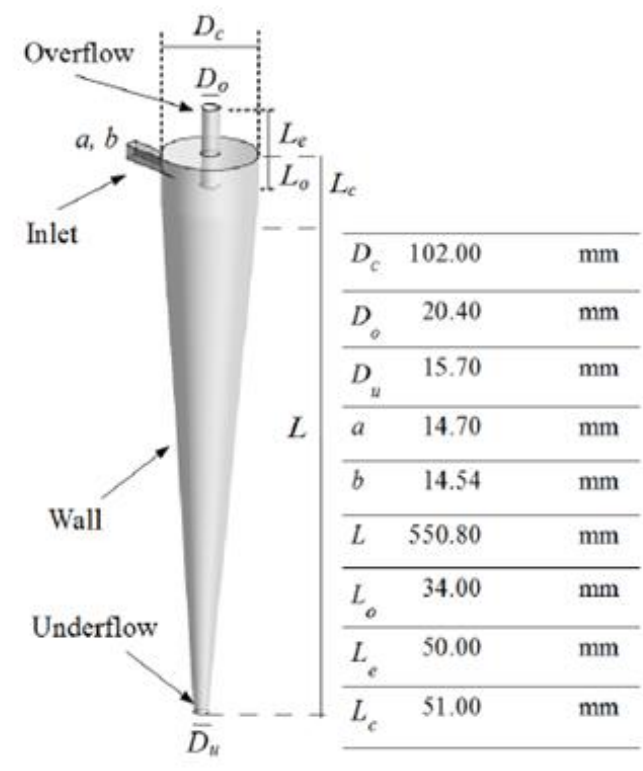

(a)

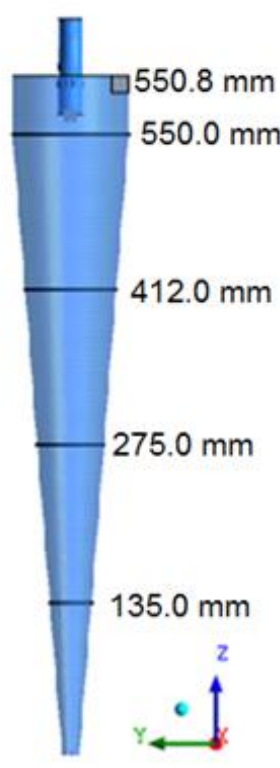

(b)

Figure 1. Hydrocyclone used in this work: (a) geometrical parameter and (b) YZ view indicating different positions along the $\mathrm{Z}$ axis.

\section{GEOMETRY DESCRIPTION}

Hydrocyclone's configuration and dimensions used in the present work are based in Bradley geometry. The input section is positioned in right side of the cylindrical portion as shown in Fig. 1. To obtain the numerical results, the experiment used a mesh, generated in the module CFX - Build 5.5, to represent the hydrocyclone. Souza et al. (2011) illustrated the details of the unstructured mesh, which was built by 42.393 nodal points and had 228.219 tetrahedral elements. The mesh also included details of the upper and lower regions of the hydrocylone.

\section{MATHEMATICAL MODEL}

\subsection{Conservation equations}

The mathematical model describes the multiphase flow within hydrocyclone, which is composed by mass (Eq. 1), momentum (Eq. 2), and energy (Eq. 3). The multiphase flow comprises the following phases: dispersed phase (heavy oil) and the continuous phase (water phase). Conservation equations and turbulence model (ANSYS CFX 11.0) are represented as follows:

$$
\frac{\partial}{\partial t}\left(f_{\alpha} \rho_{\alpha}\right)=-\nabla \bullet\left(f_{\alpha} \rho_{\alpha} \vec{U}_{\alpha}\right)
$$

$$
\begin{aligned}
& \frac{\partial}{\partial t}\left(f_{\alpha} \rho_{\alpha} \vec{U}_{\alpha}\right)+\nabla \bullet\left[f_{\alpha}\left(\rho_{\alpha} \vec{U}_{\alpha} \otimes \vec{U}_{\alpha}\right)\right]= \\
& =-f_{\alpha} \nabla p_{\alpha}+\vec{M}_{\alpha}+\nabla \bullet\left\{f_{\alpha} \mu_{\alpha}\left[\nabla \vec{U}_{\alpha}+\left(\nabla \vec{U}_{\alpha}\right)^{T}\right]\right\}
\end{aligned}
$$

$\frac{\partial}{\partial t}\left(f_{\alpha} \rho_{\alpha} h_{\alpha}\right)=Q_{\alpha}-\nabla \bullet\left[f_{\alpha}\left(\rho_{\alpha} \vec{U}_{\alpha} h_{\alpha}-\lambda_{\alpha} \nabla T_{\alpha}\right)\right]$

Where the Greek sub-indices $\alpha$ represent the involved phases of water/ultra-viscous heavy oil mixture. The symbols $f, \rho$, and $\vec{U}$ correspond to volume fraction, density, and velocity vector, respectively. For phase $\alpha$, the velocity vector is given by $\vec{U}_{\alpha}=(u, v, w) ; p$ is the pressure; $\vec{M}_{\alpha}$ describes total force (forces of interfacial drag, 
sustentation, wall lubrication, virtual mass and turbulent dispersion) per unit of volume on a continuous phase, which occurs due to the interaction with a dispersed phase; $h_{\alpha}, \mathrm{T}_{\alpha}$ and $\lambda_{\alpha}$, denote the static enthalpy, temperature and thermal conductivity of phase $\alpha$, respectively. In this work, only interfacial drag force was considered.

The drag force of continuous phase, $\alpha$, due to phase $\beta$, is given by Eq. 4 , as follows:

$$
\vec{M}_{\alpha}=c_{\alpha \beta}^{(d)}\left(\vec{U}_{\beta}-\vec{U}_{\alpha}\right)
$$

being

$$
c_{\alpha \beta}^{(d)}=\frac{3}{4} \frac{C_{D}}{d_{p}} f_{\beta} \rho_{\alpha}\left|\vec{U}_{\beta}-\vec{U}_{\alpha}\right|
$$

Where $d p$ is the particle diameter and $C_{D}$ is the drag coefficient. In this work, $C_{D}$ has been adopted to be equal to 0.44 (for the turbulent and viscous regimes).

Heat transfer across a phase boundary is usually described in terms of an overall heat transfer coefficient $h_{\alpha \beta}$, which is the amount of heat energy crossing a unit area per unit time per unit temperature difference between the phases. Thus, the rate of heat transfer, $Q_{\alpha \beta}$, per unit time across a phase boundary of interfacial area per unit volume $A_{\alpha \beta}$, from phase $\beta$ to phase $\alpha$, is:

$$
Q_{\alpha \beta}=h_{\alpha \beta} A_{\alpha \beta}\left(T_{\beta}-T_{\alpha}\right)
$$

Hence, the interfacial area per unit volume, $A_{\alpha \beta}$ and the convective heat transfer coefficient, $h_{\alpha \beta}$, are required.

The Particle model for interfacial transfer between two phases assumes that one of the phases is continuous (phase $\alpha$ ) and the other is dispersed (phase $\beta$ ). The surface area per unit volume is then calculated by assuming that phase $\beta$ is present as spherical particles of mean diameter $d_{\beta}$ and $f_{\beta}$ volume fraction. Using this model, the interphase contact area is:
$\mathrm{A}_{\alpha \beta}=\frac{6 f_{\beta}}{d_{\beta}}$

In the heat transfer problem, it is often convenient to express the heat transfer coefficient in terms of a dimensionless Nusselt number, as follows:

$$
h_{\alpha \beta}=\frac{\lambda_{\alpha} N u_{\alpha \beta}}{d_{\beta}}
$$

In the particle model, the thermal conductivity scale, $\lambda_{\alpha}$, is taken to be the thermal conductivity of the continuous phase (water), and the length scale, $d_{\beta}$, is taken to be the mean diameter of the dispersed phase (oil). The experiment used the Ranz-Marshall empirical correlation to calculate the convective heat transfer. Where, $\mathrm{Nu}$ and $\mathrm{Re}$ are the Nusselt and Particles Reynolds numbers, respectively.

$$
N u=2+0.6 \operatorname{Re}^{0.5} \operatorname{Pr}^{0.3}
$$

The Prandtl number $\left(P_{r}\right)$ is the ratio of the diffusivity of momentum and thermal diffusivity. It is calculated based on the specific heat $C_{p}$ and the viscosity of the continuous phase (water) $\mu_{\alpha}$ as follows:

$\operatorname{Pr}=\frac{C_{p} \mu}{\lambda_{\alpha}}$

The Ranz-Marshall correlation is valid for $0<R e<200$ and $0<P r<250$. Therefore, this correlation can be applied to a wide range of Reynolds numbers. The Reynolds number cross over point is chosen to maintain continuity. This number should not be used outside the recommended Prandtl number range.

\subsection{Turbulence model}

Turbulent flows occur in a large number of industrial applications. These multiphase flows are turbulent or at least "pseudo turbulent". The basic knowledge and good mathematical modeling provides, at least qualitatively, turbulence effects in a variety of practical applications. 
The general theory for turbulent flow exhibits random velocity fluctuations, although it is treated as a continuous phenomenon. Turbulence is a very complex phenomenon, which is chaotic, nonlinear, three-dimensional, inhomogeneous, and nonstationary (Kleinstreuer, 2003). The selection of the different mathematical modeling to predict turbulence effects, such as the $k-\varepsilon$, RNG $k-\varepsilon$, RSM (Reynolds-stress transport model), and LES (large eddy simulations) models depend upon the level of turbulence complexity.

The $k-\varepsilon$ model is the most widely tested turbulence model in the literature. Despite its use, there are a few situations where its results are still considered to be poor, mainly near the wall, due to the low Reynolds number in this region (Ferziger and Perić, 2002; de Lemos, 2006). The basic advantage of the $k-\varepsilon$ model over simple methods to describe turbulence is its ability to predict the length scale variation along the flow (de Lemos, 2006). In the standard $k-\varepsilon$ model, the eddy viscosity is determined from a single turbulence length scale. The calculated turbulent diffusion occurs only at the specified scale whereas, in reality, all scales of motion will contribute to the turbulent diffusion.

The RNG $k-\varepsilon$ model was developed using ReNormalisation Group (RNG) methods by Yakhot et al. (1992). This model renormalizes Navier-Stokes equations to account for the effects of smaller scales of motion. The RNG approach is a mathematical technique that can be used to derive a turbulence model similar to the $k-\varepsilon$. It results in a modified form of the $\varepsilon$ equation, which attempts to account for the different scales of motion through changes to the production term.

Due to complexity of the turbulent fluid flow inside the hydrocyclone, this research uses the $k$ $\varepsilon$ model (RNG) to complete the mathematical formulation. The renormalization group (RNG) $k$ $\varepsilon$ model is similar in form to the $k$ - $\varepsilon$ model, but includes additional terms for turbulence dissipation rate $\varepsilon$. It furnishes more accurate predictions of the flow situations, including the separation process, streamlines, curves, and stagnant regions.

The values of turbulent kinetic energy, $k$, and turbulent dissipation rate, $\varepsilon$, are directly obtained from the differential equations of transport, as can be observed in Eq. 10 and Eq. 11.

$$
\begin{aligned}
& \frac{\partial}{\partial t}(\rho k)+\nabla \bullet(\rho \vec{U} k)= \\
= & P_{k}-\rho \varepsilon+\nabla \bullet\left[\left(\mu+\frac{\mu_{t}}{\sigma_{k R N G}}\right) \nabla k\right] \\
& \frac{\partial}{\partial t}(\rho \varepsilon)+\nabla \bullet(\rho \vec{U} \varepsilon)=\nabla \bullet\left[\left(\mu+\frac{\mu_{t}}{\sigma_{\varepsilon R N G}}\right) \nabla \varepsilon\right]+ \\
+ & \frac{\varepsilon}{k}\left(C_{\varepsilon 1 R N G} P_{k}-C_{\varepsilon 2 R N G} \rho \varepsilon\right)
\end{aligned}
$$

Where $\mu$ is the dynamic viscosity, $\rho$ is the density, and $\mu_{t}$ is the turbulent viscosity which is given by (12).

$$
\mu_{t}=C_{\mu} \rho \frac{k^{2}}{\varepsilon}
$$

Where $C_{\mu}$ is an empirical constant which the values are given by:

$$
C_{\mu}=\sigma_{k N R G}=\sigma_{\varepsilon N R G}=0.7179
$$

and

$$
C_{\varepsilon 2 R N G}=1.68
$$

$C_{\varepsilon 1 R N G}=1.42-\frac{\eta\left(1-\frac{\eta}{4.38}\right)}{1+\eta^{3} \beta_{R N G}}$

Being,

$$
\eta=\sqrt{\frac{P_{k}}{\rho \varepsilon C_{\mu R N G}}}
$$


In Eq. $16, P_{k}$ is the turbulence production due to viscous and buoyancy forces or shear production of turbulence, which is modeled using Eq. 17 as follows:

$$
P_{k}=\mu_{t} \nabla \vec{U} \bullet\left(\nabla \vec{U}+\nabla \overrightarrow{U^{t}}\right)+P_{k b}
$$

The term $P_{k b}$ is the production of buoyancy and is modeled by Eq. 18 as follows:

$$
P_{k b}=-\frac{\mu_{t}}{\rho \sigma_{p}} g \nabla \rho
$$

Where $\sigma_{\rho}$ is a constant and it is equal to 1 .

\subsection{Boundary conditions}

The mixture velocity and oil volumetric fraction on the inlet of the hydrocyclone were fixed $20 \mathrm{~m} / \mathrm{s}$ and 0.3 , respectively. Inlet mixture temperature and oil droplet size varied from 10 to $100^{\circ} \mathrm{C}$ (step $10^{\circ} \mathrm{C}$ ) and 10 to $100 \mu \mathrm{m}$, respectively. The adopted inlet conditions are represented in Table 1 . In the two outlets of the hydrocyclone (overflow and underflow), the researchers adopted the prescribed average static pressure condition (atmospheric pressure, $\mathrm{P}=101325 \mathrm{~Pa}$ ).

For heavy oil and water phases, all the velocity components $(u, v, w)$ were null on the hydrocyclone's inner walls (no slip condition). The hydrocyclone wall was considered adiabatic. The wall's roughness was considered equal to 0.045 $\mathrm{mm}$. These conditions were adjusted to optimize the efficiency of separation, $E$, which was calculated considering the mass flow rate of the oil at the overflow, $W_{\text {overflow, }}$ and the mass flow rate of oil at the inlet, $W_{\text {inlet, }}$ as follows:

$$
E=\frac{W_{\text {overflow }}}{W_{\text {inlet }}} \times 100 \%
$$

The dynamic viscosity of the oil and water as a function of temperature was obtained by numerical fit with experimental data (Babadagli, 1996; Babadagli and Al-Bemani, 2007) according to Eq. 20 as follows:
Table 1 . The boundary conditions used in the simulation.

\begin{tabular}{lll}
\hline \multirow{2}{*}{ Flow parameter } & \multicolumn{2}{c}{ Fluid } \\
\cline { 2 - 3 } & Water & Oil \\
\hline$u(\mathrm{~m} / \mathrm{s})$ & 20 & 20 \\
$v, w(\mathrm{~m} / \mathrm{s})$ & 0 & 0 \\
$f$ & 0.7 & 0.3 \\
\hline
\end{tabular}

$\mu(T)=a_{1} \times e^{-b_{1} \times T_{a d m}}$

Herein $a_{1}$ and $b_{1}$ are constants equal to 3.1871 and 2.3935 for oil and 0.0009 and 2.6890 for water, respectively; $T_{a d m}$ is the non-dimensional temperature, which was calculated by using Eq. 21,

$$
T_{a d m}=\frac{\left(T-T_{\min }\right)}{\left(T_{\max }-T_{\min }\right)}
$$

Where $T_{\max }=593 \mathrm{~K}$ and $T_{\min }=273 \mathrm{~K}$.

\section{RESULTS AND DISCUSSION}

Results of numerical simulations for two-phase flow of water/heavy oil mixture, inside the hydrocyclone were obtained in a 3.0GHz QuadCore computer, with RMS convergence criterion equal to $10^{-6}$. Numerical simulations were carried out considering a steady state regime, in the presence of heat transfer. The composition of the fluid at the entrance of the equipment was kept constant, varying only the temperature and oil droplet diameter. In the conservation equations, convective terms were treated using the high resolution advection scheme.

Fig. 2 illustrates the effects of the inlet temperature on the oil viscosity. One can observe clearly a decrease in oil viscosity from the 1.9 to $1.11 \mathrm{~Pa}$.s when inlet mixture temperature ranged from 10 to $100^{\circ} \mathrm{C}$. The same result was reported by Babadagli (1996); Bennett and Williams (2004); Hashmi et al. (2004); and Babadagli and Al-Bemani (2007).

Figures 3 and 4 show the effects of particle diameter and temperature on the oil superficial velocity inside the hydrocyclone in the $Z Y$ plane for 


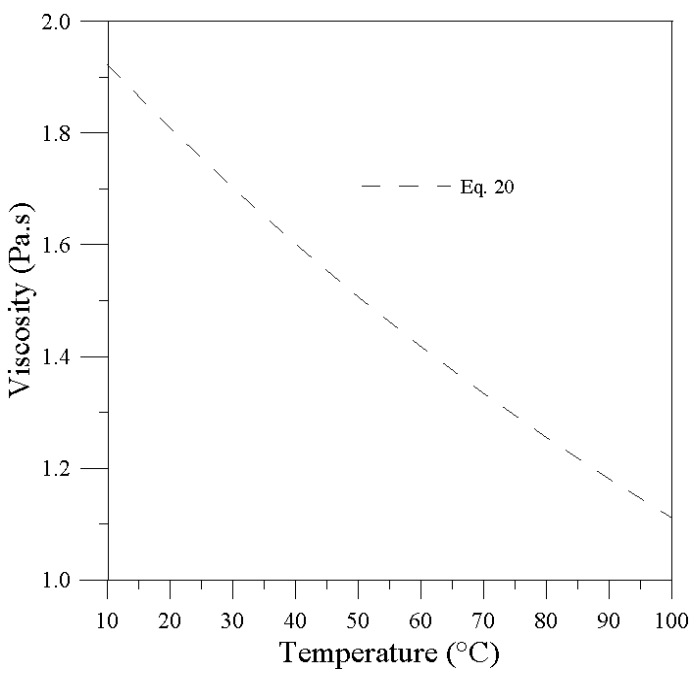

Figure 2. Oil viscosity as a function of inlet fluid mixture temperature.

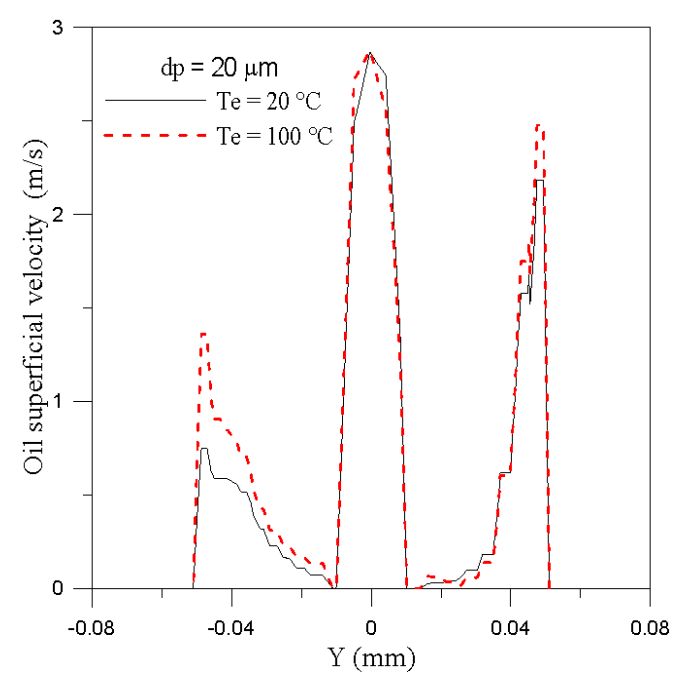

Figure 3. Oil superficial velocity on the plane $\mathrm{Z}=550.8 \mathrm{~mm},(X=0 \mathrm{~mm}, \mathrm{dp}=20 \mu \mathrm{m})$.

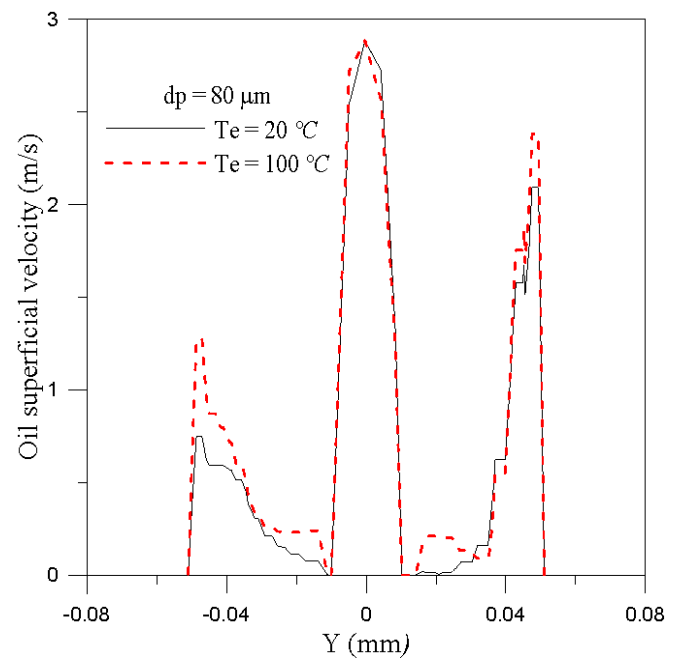

Figure 4. Oil superficial velocity on the plane $\mathrm{Z}=550.8 \mathrm{~mm}(\mathrm{X}=0 \mathrm{~mm}, \mathrm{dp}=80 \mu \mathrm{m})$. increase of inlet mixture temperature from 20 to $100^{\circ} \mathrm{C}$, and oil droplet size from 20 to $80 \mu \mathrm{m}$, increases oil's superficial velocity. This occurs due to the heat transfer between water and heavy oil, providing a reduction in the heavy oil viscosity. This reduction in fluid viscosity allows the fluid to flow more easily.

Figure 5 illustrates the effect of oil particle diameter on the oil superficial velocity inside the hydrocyclone in the $Z Y$ plane, for $Z=550.8 \mathrm{~mm}$, when inlet temperature was fixed in $100^{\circ} \mathrm{C}$. The oil droplet size has few influences on the oil's superficial velocity.

Figures 6 and 7 illustrate the numerical results of separation efficiency of the hydrocyclone as a function of oil droplet size and inlet mixture temperature, respectively. With the purpose of comparing the effects of oil droplet diameter on the separation efficiency, inlet temperatures were fixed at 20 and $100^{\circ} \mathrm{C}$, and inlet velocity was fixed at $20 \mathrm{~m} / \mathrm{s}$. These comparisons show that the separation efficiency increases with increased oil droplet size (until $40 \mu \mathrm{m}$ ) and with the increase in inlet temperature' as reported by Bennett and Williams (2004) and Hashmi et al. (2004).

The separation efficiencies for different temperatures were obtained for fixed values, that is: inlet mixture velocity and oil droplet diameter of $20 \mathrm{~m} / \mathrm{s}$ and $40 \mu \mathrm{m}$, respectively, as illustrated in Fig. 7. The graph shows an increase in separation efficiency reaching $60.11 \%$ for temperature of $100^{\circ} \mathrm{C}$.

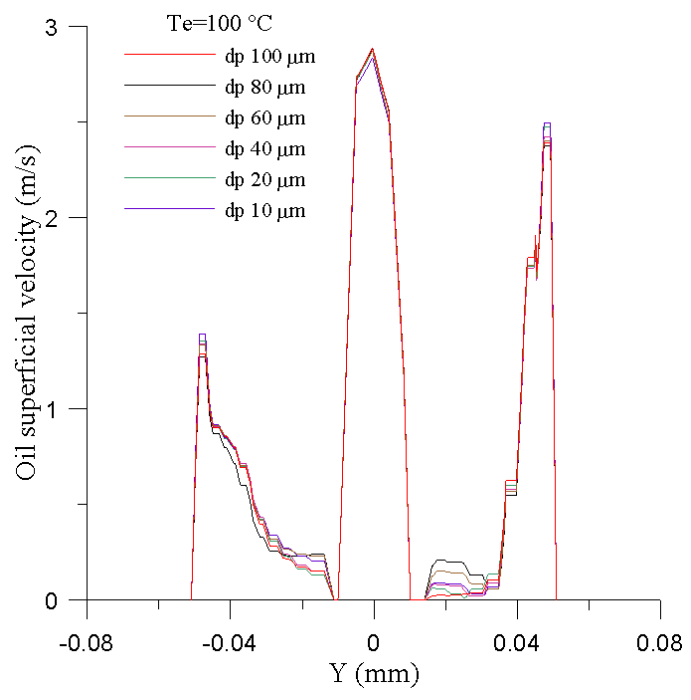

Figure 5. Oil superficial velocity on the plane $\mathrm{Z}=550.8 \mathrm{~mm}\left(\mathrm{X}=0 \mathrm{~mm}, \mathrm{Te}=100^{\circ} \mathrm{C}\right)$. 


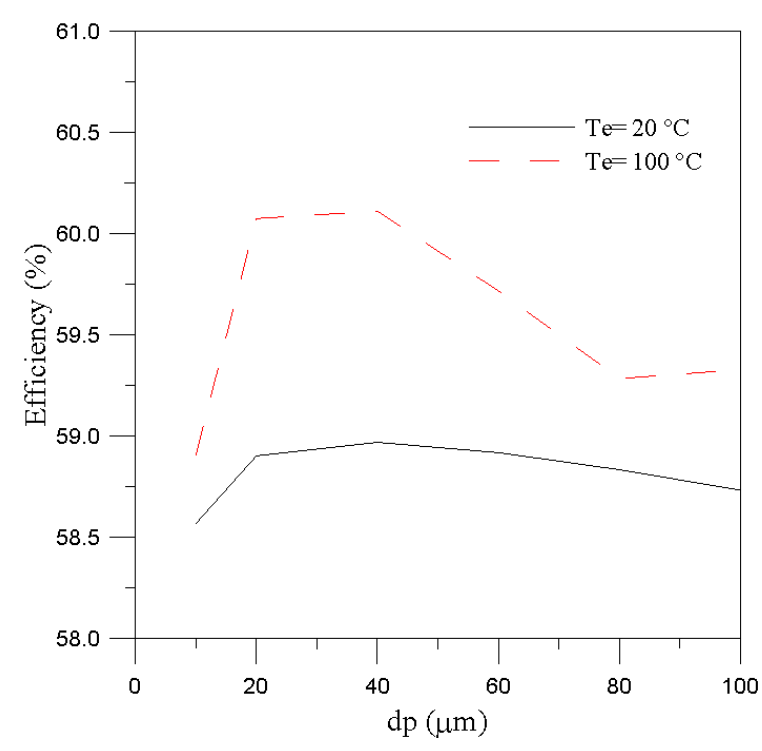

Figure 6. Removal efficiency as a function of oil droplet diameter.

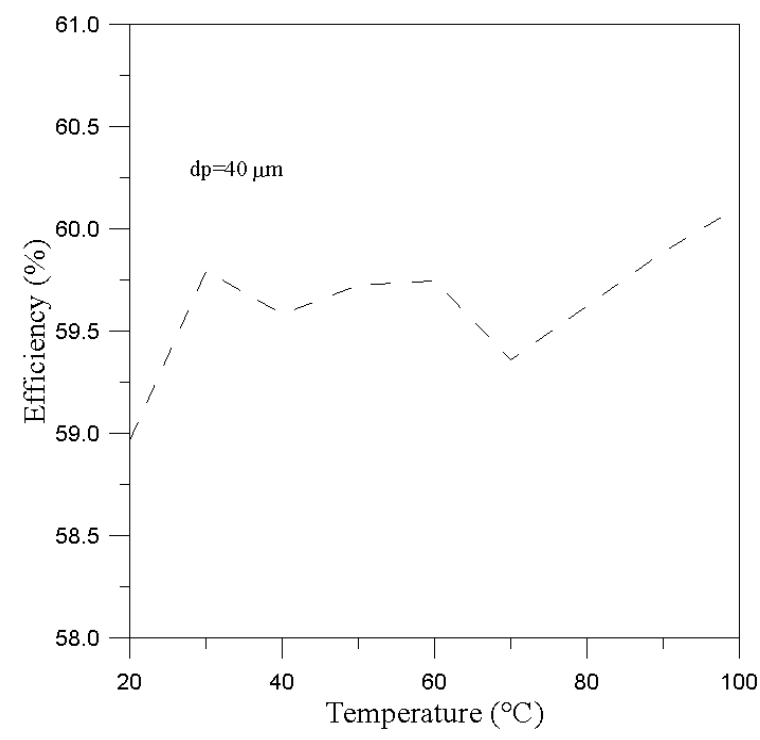

Figure 7. Hydrocyclone separation efficiency as a function of inlet mixture temperature.

According to Hashimi et al. (2004), for high oil concentration $(\approx 30 \%)$, separation efficiency is very low. Besides, Farias et al. (2010) reports a separation efficiency of a hydrocyclone changing from 56.30 to $57.70 \%$ for work conditions $\mathrm{dp}=100 \mu \mathrm{m}$, oil volume fraction $30 \%$, inlet mixture velocity $15-30 \mathrm{~m} / \mathrm{s}$ at environmental temperature. Similar results were verified herein, using a $30 \%$ concentration at feed inlet.

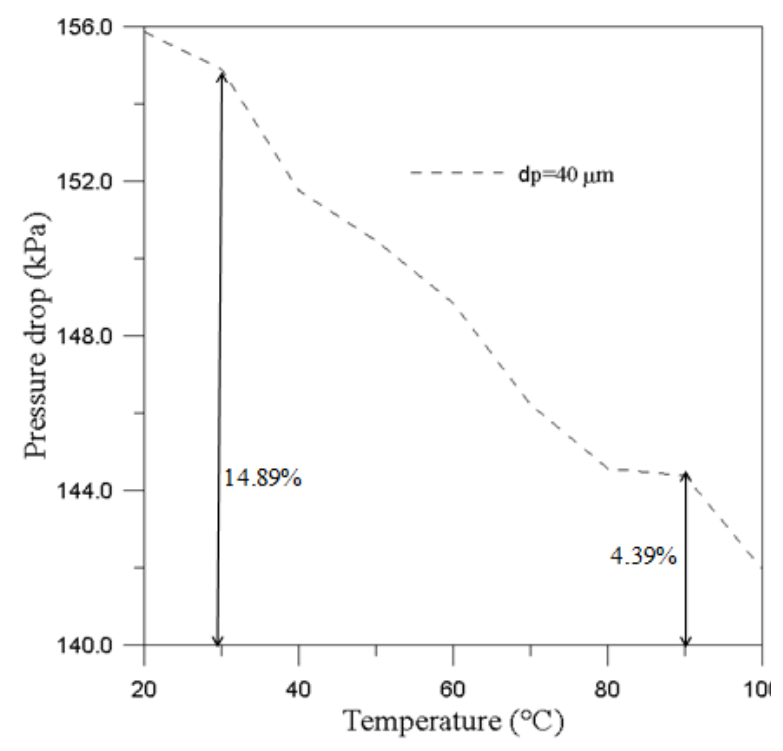

Figure 8. Pressure drop as a function of inlet fluid mixture temperature.

The maximum pressure drop, necessary to move the water/oil mixture into the hydrocyclone, is presented as a function of the temperature in Figure 8. This performance is achieved with the pressure difference between the feed and the overflow. Herein, fixed values were used, inlet mixture velocity of $20 \mathrm{~m} / \mathrm{s}$ and oil droplet diameter of $40 \mu \mathrm{m}$. This result evidences the decrease the pressure drop with the increase of the inlet mixture temperature. This behavior relates to the reduction in the friction between particles and inner walls, including outlet duct (overflow) of the equipment. This happens because the decrease in oil viscosity reduces the energy consumption of the separation process. Looking at the data, one can observe a reduction in pressure drop of $14.89 \%$ reached at $30^{\circ} \mathrm{C}$, while a reduction of $4.39 \%$ was reached at a temperature of $90^{\circ} \mathrm{C}$.

Figure 9 illustrates the pressure field on the $Z Y$ planes into the hydrocyclone $(X=0 \mathrm{~mm})$ for different inlet mixture temperature and oil droplet diameter fixed at $100 \mu \mathrm{m}$. Observing these figures, it is possible to notice low pressure regions near the central axis of the hydrocyclone and higher pressures in the regions near the walls and the tangential inlet of the hydrocyclone. This behavior is attributed to gravitational and friction forces that are act in these regions, being more intense in lower inlet mixture temperature. 


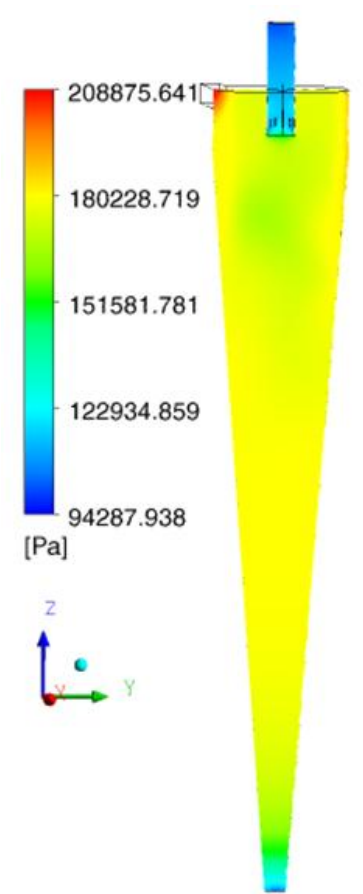

(a)

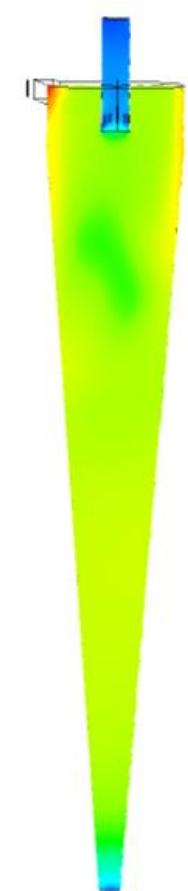

(b)
Figure 9. Representation of the pressure distribution on the $\mathrm{ZY}$ plane, $\mathrm{dp}=100 \mu \mathrm{m}$ for (a) $\mathrm{Te}=20^{\circ} \mathrm{C}$ and $(\mathrm{b}) \mathrm{Te}=100^{\circ} \mathrm{C}$.

When the inlet temperature is $20^{\circ} \mathrm{C}$, the pressure drop reached $114.137 \mathrm{kPa}$ and for $100^{\circ} \mathrm{C}$ this value was $112.407 \mathrm{kPa}$. Thus, by increasing the inlet mixture temperature less energy is required for pumping the mixture into the hydrocyclone.

\section{CONCLUSIONS}

The simulation results revealed the importance of considering the influence of heat transfer on the oil/water separation process by hydrocyclone, especially for mixtures with high oil viscosity. When a higher inlet mixture temperature is used, a significant reduction in viscosity occurs, thus, resulting in a higher oil mass flow rate on the overflow. Also, the use of a higher inlet mixture temperature leads to a higher hydrocyclone separation efficiency. An increase on the oil droplet size from 10 to $100 \mu \mathrm{m}$ affects slightly oil superficial velocity and separation efficiency of the hydrocyclone. A decrease in difference of pressure drop between inlet and outlet (overflow) of $13.89 \mathrm{kPa}$ and oil viscosity of $57.89 \%$ provides an increase in hydrocyclone separation efficiency from
58.56 to $60.11 \%$, when inlet mixture temperature changed from 20 to $100^{\circ} \mathrm{C}$. The maximum separation efficiency was reached when the experiment used an inlet mixture temperature of $100^{\circ} \mathrm{C}$ and an oil droplet of $40 \mu \mathrm{m}$.

\section{ACKNOWLEDGEMENTS}

The authors would like to express their thanks to Brazilian research agencies CNPq, CAPES, FINEP, and PETROBRAS for supporting this work. They would also like to express their gratitude to the authors of the references made on this paper, which helped to improve its quality.

\section{NOMENCLATURE}

L Length conical part of the [m] hydrocyclone

$L_{0} \quad$ Length cylindrical part of the [m] hydrocyclone

$L_{c} \quad$ Length of the hydrocyclone [m]

$L_{e} \quad$ Length of the vortex finder [m]

$C_{1} \quad$ Constant of the turbulence [- ] model

$C_{2} \quad$ Constant of the turbulence [ - ] model

$C \mu \quad$ Empirical constant $\quad[-]$

$d p \quad$ Particle diameter $\quad$ [m]

$\begin{array}{lll}D_{c} & \text { Hydrocyclone diameter }\end{array}$

$D_{u} \quad$ Underflow diameter $\quad[\mathrm{m}]$

Do Vortex finder diameter [m]

$a, b \quad$ Inlet duct dimensions [m]

$E \quad$ Separation efficiency [\%]

$k \quad$ Turbulent kinetic energy $\quad\left[\mathrm{m}^{2} \mathrm{~s}^{-2}\right]$

$h_{\alpha \beta} \quad$ Convective heat transfer $\quad\left[\mathrm{W} \mathrm{m}^{-2} \mathrm{~K}^{-1}\right]$ coefficient

$h_{\alpha} \quad$ Static enthalpy $\quad\left[\mathrm{m}^{2} \mathrm{~s}^{-2}\right]$

$M_{\alpha} \quad$ Total force of phase $\alpha$, through [N] interaction with other phases

$f \quad$ Volumetric fraction [ - ]

$N_{u} \quad$ Nusselt Number [ - ]

$\begin{array}{lll}P_{r} & \text { Prandtl Number } & \text { [ ] }\end{array}$

Re Reynolds Number [- ]

$p \quad$ Pressure [Pa]

$P_{k b} \quad$ Buoyancy production $\quad\left[\mathrm{kg} \mathrm{m}^{-1} \mathrm{~s}^{-3}\right.$.

$P_{k} \quad$ Turbulence production $\quad\left[\mathrm{kg} \mathrm{m}^{-1} \mathrm{~s}^{-3}\right.$.

RNG Renormalization Group Theory [ - ]

$\mathrm{T}_{\mathrm{e}} \quad$ Inlet temperature [K] 


$\begin{array}{llr}Q_{\alpha} & \text { Interfacial Heat transfer } & {\left[\mathrm{W} \mathrm{m}^{-3}\right]} \\ W & \text { Mass flow rate } & {\left[\mathrm{kg} \mathrm{s}^{-1}\right]} \\ W_{\text {inlet }} & \text { Inlet mass flow rate } & {\left[\mathrm{kg} \mathrm{s}^{-1}\right]} \\ W_{\text {overflow }} & \text { Overflow mass flow rate } & {\left[\mathrm{kg} \mathrm{s}^{-1}\right]} \\ \vec{U} & \text { Velocity vector } & {\left[\mathrm{m} \mathrm{s}^{-1}\right]} \\ \lambda_{\alpha} & \text { Thermal Conductivity } & {\left[\mathrm{W} \mathrm{m}^{-1} \mathrm{~K}^{-1}\right]} \\ \sigma_{\rho} & \text { Constants equal unity } & {[-]} \\ \sigma_{\mathrm{k}}, \sigma_{\varepsilon} & \text { Constants turbulence model } & {[-]} \\ \rho & \text { Density } & {\left[\mathrm{kg} \mathrm{m}^{-3}\right]} \\ \rho_{\alpha \beta} & \text { Mixture density } & {\left[\mathrm{kg} \mathrm{m}^{-3}\right]} \\ \alpha, \beta & \text { Involved phases } & {[-]} \\ \varepsilon & \text { Dissipation turbulent rate } & {\left[\mathrm{m}^{2} \mathrm{~s}^{-3}\right]} \\ \mu & \text { Dynamic viscosity } & {[\mathrm{Pa} \mathrm{s}]} \\ \mu_{\tau} & \text { Turbulent viscosity } & {[\mathrm{Pa} \mathrm{s}]}\end{array}$

\section{REFERENCES}

Ahmadun, F.R.; Pendashteh, A.; Abdullah, L. C. Biak, D. R. A.; Madaeni, S. S.; Abidin, Z. Z. Review of technologies for oil and gas produced water treatment. Journal of Hazardous Materials, v. 170(2-3), p. 530-551, 2009.

http://dx.doi.org/10.1016/j.jhazmat.2009.05.044

ANSYS CFX, "User Manual Theory," ANSYS CFXSolver Theory Guide, ANSYS Inc., Canonsburg, 2009.

Babadagli, T. Temperature effect on heavy-oil recovery by imbibition fractured reservoirs, Journal of Petroleum Science and Engineering, v. 14(1-2), p. 196-208, 1996.

Babadagli, T.; Al-Bemani, A. Investigations on matrix recovery during steam injection into heavyoil containing carbonate rocks. Journal of Petroleum Science and Engineering, v. 58(1-2), p. 259-274, 2007.

http://dx.doi.org/10.1016/i.petrol.2007.01.003

Bennett, M. A.; Williams, R. A. Monitoring the operation of an oil/water separator using impedance tomography. Minerals Engineering, v. 17(5), p. 605-614, 2004.

http://dx.doi.org/10.1016/j.mineng.2004.01.021

Cilliers, J. J.; Diaz-Anadon L.; Wee, F. S. Temperature, classification and dewatering in 10 $\mathrm{mm}$ hydrocyclones. Minerals Engineering, v. 17(5), p. 591-597, 2004.

http://dx.doi.org/10.1016/i.mineng.2003.11.022 de Lemos, M.S. Turbulence in porous media. Amsterdam, Elsevier, 2006.

Farias, F.P.M.; Burity, C.J.O.; Lima, W.C.P.B.; Farias Neto, S.R.; Lima, A.G.B. The effect of droplet diameter on the separation of heavy-oil from water using a hydrocyclone. Defect and Diffusion Forum, v. 303-304, p. 131-137, 2010.

Farias, F.P.M.; Souza, J.S.; Lima, W.C.P.B.; Macêdo, A.C.; Farias Neto, S.R.; Lima, A.G.B. Influence of Geometric Parameters of the hydrocyclone and sand concentration on the water/sand/heavy-oil separation process: Modeling and Simulation. The International Journal of Multiphysics, v. 5(5), p. 187-202, 2011. http://dx.doi.org/10.1260/1750-9548.5.3.187

Ferziger, J. H.; Perić, M. Computational methods for fluid dynamics. Berlin, Springer, 2002. http://dx.doi.org/10.1007/978-3-642-56026-2

Hashmi, K. A.; Hamza, H. A.; Wilson, J. C. CANMET hydrocyclone: an emerging alternative for the treatment of oily waste streams. Minerals Engineering, v. 17(5), p. 643-649, 2004.

http://dx.doi.org/10.1016/i.mineng.2004.01.019

Husveg, T.; Rambeau, O.; Drengstig, T.; Bilstad, T. Performance of deoling hydrocyclone during variables flow rates. Minerals Engineering, v. 20(4), p. 368-379, 2007.

http://dx.doi.org/10.1016/i.mineng.2006.12.002

Kleinstreuer, C. Two-phase flow: theory and applications. New York, Taylor \& Francis, 2003.

Neff, J.M., Bioaccumulation in marine organisms: effect of contaminants from oil well produced water, Elsevier, The Netherlands, 2002.

Souza, J. S.; Farias, F. P. M.; Swarnakar, R.; Farias Neto, S. R.; Lima, A.G. B. Non-isothermal separation process of two-phase mixture water/ultra-viscous heavy oil by hydrocyclone. Advances in Chemical Engineering and Science, v. 1(4), pp. 271-279, 2011. http://dx.doi.org/10.4236/aces.2011.14038

Vieira, T. M.; Souza, J. S.; Barbosa, E. S.; Cunha, A. L.; Farias Neto, S. R.; Lima, A. G. B. Numerical Study of oil/water separation by ceramic membranes in the presence of turbulent flow. Advances in Chemical Engineering and Science, v. 2(2), p. 257-265, 2012. http://dx.doi.org/10.4236/aces.2012.22030 
Xiang, R. B.; Lee, K. W. Numerical study of flow field in cyclones of different height. Chemical Engineering and Process, v. 44(8), p. 877-883, 2005. http://dx.doi.org/10.1016/j.cep.2004.09.006

Yakhot, V.; Orszag, S.A.; Thangam, S.; Gatski, T.B; Speziale, C.G. Development of turbulence models for shear flows by a double expansion technique. Physics of Fluids A, v. 4(7), p. 15101520, 1992. http://dx.doi.org/10.1063/1.858424
Yoshida, H.; Takashina, T.; Fukuia, K.; Iwanaga, T. Effect of inlet shape and slurry temperature on the classification performance of hydrocyclones. Powder Technology, v. 140(1-2), p. 1- 9, 2004. http://dx.doi.org/10.1016/i.powtec.2003.12.006 